\title{
PROTOTYPE SISTEM SMART LOCK DOOR DENGAN TIMER DAN FINGERPRINT SEBAGAI ALAT AUTENTIKASI BERBASIS ARDUINO UNO PADA RUANGAN
}

\author{
Erick Febriyanto ${ }^{1}$, adeli $^{2}$, Danang Suprayogi ${ }^{3}$ \\ Jurusan Sistem Komputer, STMIK Raharja, Tangerang \\ e-mail: 1erick@raharja.info, ${ }^{1}$ padeli@raharja.info, ${ }^{3}$ danang.suprayogi@raharja.info
}

\begin{abstract}
Security is a matter that must be often ignored by most people and considers it safe, but in fact someone can still lose his valuables. For example in a room where security is often considered good by most people just by locking the door provided, but often people forget to lock the door. Because forgetting to lock the room door causes someone to lose his valuables. The development of technology that has increasingly sophisticated door security systems must keep abreast of the times. Room door security systems that are currently still using conventional methods are considered insecure at this time, even though there is already a CCTV camera that has been used to monitor the room. Therefore the media is used to make a room safer by locking the room with a timer and fingerprint. If the room occupant forgets to lock the door, the automatic door is locked according to the time specified. When in the room the door will not be locked, but if the occupants want to leave the room and forget to lock the room is automatically locked and when you want to open it using only fingerprints. In research conducted by researchers used a qualitative approach, namely by explaining the problem more specifically to the data or facts obtained. For fingerprint data before use, register is done so that fingerprint data is registered on the system and can be used.
\end{abstract}

Keywords : Autentifikasi, Fingerprint, Timer

\begin{abstract}
ABSTRAK
Keamanan merupakan suatu hal yang harus sering kali diabaikan oleh kebanyakan orang dan menganggap sudah aman, namun nyatanya seseorang masih dapat kehilangan barang berharga miliknya. Contohnya pada ruangan yang keamanannya seringkali dianggap sudah baik oleh kebanyakan masyarakat hanya dengan mengunci pintu yang telah disediakan, namun sering juga masyarakat lupa mengunci pintu. Karena lupa mengunci pintu ruangan mengakibatkan seseorang kehilangan barang berharga miliknya. Perkembangan teknologi yang sudah semakin canggih sistem keamanan pintu harus mengikuti perkembangan jaman. Sistem keamanan pintu ruangan yang saat ini masih menggunakan metode konvensional dirasa kurang aman saat ini, walaupun sudah ada kamera cctv yang sudah digunakan untuk memantau ruangan. Maka dari itu digunakanlah media untuk membuat sebuah ruangan lebih aman dengan mengunci ruangan dengan timer dan fingerprint. Jika penghuni ruangan lupa untuk mengunci pintu, maka pintu otomatis terkunci berdasarkan waktu yang ditentukan. Ketika berada didalam ruangan maka pintu tidak akan terkunci, namun jika penghuni ingin keluar ruangan dan lupa mengunci maka ruangan sudah otomatis terkunci dan ketika ingin membukanya hanya menggunakan sidik jari. Dalam penelitian yang dilakukan oleh peneliti digunakan pendekatan secara kualitatif, yaitu dengan menjelaskan masalah secara lebih spesifik terhadap data atau fakta yang didapatkan. Untuk data sidik jari sebelum digunakan dilakukan register agar data sidik jari terdaftar pada sistem dan dapat digunakan.
\end{abstract}

Ruang Kunci: Otentifikasi, Sidik Jari, Waktu 


\section{PENDAHULUAN}

Hampir seluruh aspek kehidupan saat ini menggunakan teknologi dalam penerapan sehari - hari. Dari pendidikan, kegiatan berniaga, perkantoran, hingga pemerintahan saat ini sudah menggunakan teknologi untuk membantu kegiatannya. Tidak menutup kemungkinan juga seiring berkembangnya teknologi yang begitu pesat semakin banyak pula tindak kejahatan yang memanfaatkan teknologi untuk melakukannya. Seperti Hacking, Cracking hingga Tracking, itu semua tindak kejahatan yang memanfaatkan teknologi untuk melakukannya melalui internet.

Selain tindak kejahatan yang dilakukan melalui internet, banyak juga tindak kejahatan yang dilakukan dalam dunia nyata misal perampokan atau pencurian. Dengan semakin maraknya tindak kejahatan maka tingkat keamanan perlu ditingkatkan juga seiring berkembangnya zaman. Pada penelitian yang penulis lakukan saat ini tingkat keamanan dalam sebuah perkantoran masih sangat kurang walau sudah adanya kamera CCTV yang dapat memantau terus menerus. Namun jika dilihat dari tingkat keamanannya kamera CCTV masih dapat dimanipulasi.
Setelah melewati CCTV ketika ingin masuk ke dalam ruangan pastinya seorang yang ingin melakukan tindak kejahatan harus melewati pintu ruangan tersebut. Jika pemilik ruangan lupa dalam mengunci ruangan tersebut maka pencuri dapat dengan mudah masuk ke ruangan tersebut dan mengambil berkas atau arsip penting yang berada dalam ruangan tersebut. Berbeda halnya ketika ruangan tersebut dikunci secara otomatis berdasarkan waktu yang telah ditetapkan. Pencuri tidak bisa sembarang masuk kedalam ruangan tersebut. Selain menggunakan pengunci pintu otomatis keamanan dapat ditingkatkan dengan menggunakan sensor Fingerprint. Dengan adanya sensor fingerprint dapat memfilter orang yang dapat memasuki ruangan tersebut berdasarkan sidik jari yang telah terdaftar di sistem dan dengan sensor tersebut pemilik ruangan dapat mengunci atau membuka ruangan di luar dari waktu yang telah ditetapkan sebelumnya. Sehingga dapat meminimalisir tindak kejahatan yang ingin mengambil barang berharga yang berada di ruangan tersebut.

\section{METODE PENELITIAN}

Dalam penelitian yang dilakukan oleh peneliti digunakan pendekatan secara 
kualitatif, yaitu dengan menjelaskan masalah secara lebih spesifik terhadap data atau fakta yang didapatkan. Pendekatan ini digunakan oleh peneliti karena pada penelitian ini dilakukan dengan tujuan untuk mendeskripsikan atau menjelaskan fakta serta data yang telah ada, serta melakukan analisa untuk mengetahui hal apa saja yang harus dikembangkan untuk mendapatkan pemecahan masalah yang diinginkan dalam waktu yang singkat..

Metode yang digunakan pada penelitian ini yakni metode penelitian studi pustaka dan observasi. Metode penelitian studi pustaka yaitu metode penelitian yang mencari penelitian serupa yang dilakukan oleh peneliti untuk mendapatkan sebuah referensi pemecahan masalah yang sedang dialami. Sedangkan metode penelitian observasi merupakan metode penelitian yang mengumpulkan data atau fakta yang ada di lapangan untuk mencari masalah yang dihadapi serta memecahkan permasalahan tersebut dengan data atau fakta yang didapatkan.

Pada beberapa perkantoran banyak sekali yang mengabaikan keamanan ruangan yang ditempati. Padahal jika dilihat dari sisi keamanan metode penguncian optional masih mudah dibobol oleh pencuri atau oknum yang ingin bertindak jahat. Maka dari itu peneliti mencari cara bagaimana agar pintu sebuah ruangan pada kantor tidak mudah dibobol oleh pencuri. Proses analisa data yang dilakukan oleh peneliti melalui beberapa tahapan sebagai berikut : 1) melakukan evaluasi terhadap data yang didapatkan pada saat melakukan observasi. 2) mengelompokkan data agar mudah dalam mengambil kesimpulan nantinya. 3) memberikan kode pada data yang sudah didapatkan guna untuk memudahkan mengidentifikasinya.

Tujuan dari penelitian ini guna melihat seberapa efisien diterapkannya prototype pengunci pintu otomatis dengan disertai fingerprint untuk meningkatkan keamanan ruangan. Dikarenakan semakin pesatnya perkembangan teknologi maka peningkatan keamanan juga harus ditingkatkan mengikuti perkembangan teknologi. Hal tersebut tentunya akan membuat rasa aman pada beberapa perkantoran atau lembaga lainnya untuk menjaga arsip dokumen yang mereka miliki.

Selain itu juga teori yang digunakan berguna untuk membantu tercapainya tujuan pada penelitian ini. Berikut beberapa teori yang berkaitan dengan penelitian ini :

(Definisi Analisa, Definisi Sistem, Definisi Prototype, Definisi Mikrokontroller, Definisi Fingerprint) 
Menurut Iqbal (2004) yang mengemukakan bahwa sidik jari merupakan karakteristik alami manusia yang digunakan dalam identifikasi personal sejak lama. Bahkan orang awam sering menganggap sidik jari merupakan sinonim dari biometrik. Sidik jari yang terdiri dari pola alur (ridge) dan lembah (valley), yang unik untuk tiap individu, bahkan bagi mereka yang kembar sekalipun.

Untuk mendukung sebuah penelitian diperlukan juga sebuah literatur penelitian yang sudah pernah dilakukan sebelumnya. Berikut merupakan beberapa literatur penelitian yang serupa :

1. Penelitian yang dilakukan oleh Heru Supriyono, Alwi Kurniawan, dan Aris Rakhmadi (2013) dengan judul penelitian "Perancangan dan Pembuatan Sistem Pintu Otomatis menggunakan Barcode”. Pada penelitian ini membahas pada sebuah ruangan banyak sekali orang yang keluar masuk sehingga perlu adanya pengawasan untuk direkam datanya siapa saja yang memasuki ruangan tersebut. Maka dibuatlah sebuah sistem pintu masuk otomatis dengan menggunakan barcode berbasis mikrokontroler dan komputer.

2. Penelitian yang dilakukan oleh Jeprianto Rurungan, Deny Wiria
Nugraha, dan Yusuf Anshori (2014) dengan judul "SISTEM PENGAMAN PINTU OTOMATIS MENGGUNAKAN RADIO FREQUENCY IDENTIFICATION (RFID) TAG CARD DAN PERSONAL IDENTIFICATION NUMBER (PIN) BERBASIS MIKROKONTROLER AVR ATMEGA 128”. Pada penelitian ini membahas untuk mengetahui cara kerja sensor Passive Infrared sebagai alat detektor dan cara memanfaatkan sensor Passive Infrared sebagai alat keamanan ruangan yang memicu adanya sms ke Handphone, mengaktifkan lampu dan alarm. Sehingga keamanan sebuah ruangan terjamin dengan adanya sensor tersebut.

3. Penelitian yang dilakukan oleh Asep Abdul Sofyan, Puput Puspitorini, dan Dede Baehaki (2017) dengan judul “SISTEM

KEAMANAN PENGENDALI PINTU OTOMATIS BERBASIS RADIO FREQUENCY IDENTIFICATION

DENGAN ARDUINO UNO R3”. Pada penelitian ini membahas Banyaknya siswa-siswa yang berkunjung ke ruang kelas lain ketika jam mata pelajaran guru yang kosong. Terjadinya beberapa kali 
kehilangan peralatan yang ada di ruang kelas atau di ruang laboratorium sehingga keamanannya kurang terjaga dengan baik. Untuk itu dibutuhkan sistem pengontrolan pintu secara otomatis sehingga sekolah dapat mengurangi biaya pengeluaran menjadi lebih ringan.

4. Penelitian yang dilakukan oleh Raden Budiarto (2018) dengan judul “Kinerja Algoritma Pengenalan Wajah untuk Sistem Penguncian Pintu Otomatis Menggunakan Raspberry-Pi”. Pada penelitian ini membahas sistem pengenalan wajah menggunakan Raspberry Pi yang diterapkan pada sebuah prototipe pengunci pintu. Metode yang digunakan yakni mengambil sampel dataset kemudian mengevaluasi dan membandingkan algoritma pembelajaran untuk dianalisis tingkat keakuratan dan kecepatan dalam mengenali wajah.

5. Penelitian yang dilakukan oleh Muhammad Nur (2016) dengan judul “MINIATUR PENGAMAN PINTU OTOMATIS BERBASIS MIKROKONTROLER”. Pada penelitian ini membahas Pengrusakan dan pembobolan pintu rumah oleh orang yang tidak bertanggung jawab sering terjadi pada masa sekarang, maka sistem pengamanan perlu ditingkatkan agar dapat terhindar dari tindak kejahatan. Maka penggunaan keypad dan Solenoid sebagai sistem pengaman rumah dinilai cukup aman dan lebih efektif.

6. Penelitian yang dilakukan oleh Andi Apriadi, Surya Michrandi Nasution dan Fairuz Azmi (2016) dengan judul "PERANCANGAN

OTENTIKASI SIDIK JARI PADA SISTEM BIOMETRIC

PAYMENT”. Pada penelitian ini membahas Dalam kehidupan seharihari orang menggunakan kartu kredit untuk belanja. Kunci tersebut dapat berupa kata password atau PIN (Personal Indentifier Number). Permasalahan yang terjadi adalah bahwa seseorang harus mengambil banyak kartu dan harus mengingat password. Saat ini sudah banyak digunakan kunci berupa biometrik anggota tubuh manusia. Anggota tubuh manusia yang sering digunakan adalah pola retina, garis telapak tangan, dan sidik jari. Sidik jari mempunyai sifat yang unik untuk setiap individu dan mempunyai sifat yang konsisten.

7. Pada penelitian yang dilakukan oleh Junaidi Junaidi, Ladyca Anugrah, 
dan Adhitya Dwi Pancasakti (2015) dengan judul "Model Aplikasi Monitoring Sistem Absensi Sidik Jari Sebagai Pendukung Keputusan Untuk Penilaian Kinerja Pegawai”. Pada penelitian ini membahas Aplikasi sistem monitoring absensi menggunakan sidik jari merupakan suatu aplikasi pemrograman yang mampu mendukung penilaian kinerja pegawai. Aplikasi ini diharapkan dapat membantu menyelesaikan masalah-masalah yang ada di bagian sumber daya manusia umumnya dan bagian administrasi personalia khususnya.

8. Penelitian yang dilakukan oleh Ryan Wahyudi, Oni Soesanto, dan Muliadi Muliadi (2016) dengan judul "RANCANG BANGUN APLIKASI PENGENALAN POLA SIDIK JARI”. Pada penelitian ini membahas identifikasi biometrik yang umum digunakan saat ini adalah pengenalan sidik jari. Dengan menggunakan sidik jari proses identifikasi seseorang menjadi lebih mudah dan cepat karena setiap orang memiliki sidik jari yang berbeda beda.

\section{HASIL DAN PEMBAHASAN}

\subsection{Analisa permasalahan}

Perkembangan teknologi yang sangat pesat saat ini membuat tingkat keamanan semakin dipertanyakan. Oknum yang berniat jahat dapat memanfaatkan teknologi untuk membobol sistem keamanan yang sudah ada walau sudah dipersiapkan dengan baik dan hati-hati. Khususnya pada sebuah ruangan keamanan juga perlu ditingkatkan selain dengan menempatkan kamera CCTV di beberapa sudut ruangan. Penguncian pintu ruangan menjadi hal yang sangat penting dilakukan. Hal ini dikarenakan setiap orang bisa saja lupa dalam mengunci pintu ruangan tersebut, karena sifat lupa tidak bisa dihilangkan dari manusia. Sistem pengamanan sebuah ruangan dengan mengunci pintu menggunakan anak kunci masih sangat mudah dibobol. Walaupun sudah terlihat oleh kamera CCTV pengambilan dokumen atau arsip penting tidak dapat dihindari lagi. Selain itu juga terkadang penghuni ruangan seringkali lupa untuk mengunci ruangan, sehingga membuat pelaku yang ingin bertindak kejahatan memiliki kesempatan untuk melakukan tindak kejahatan.

Dengan adanya permasalahan tersebut maka penelitian ini masih memiliki masalah yang harus dipecahkan untuk menghindari kejadian tersebut. Selain itu juga dengan adanya permasalahan tersebut dapat membuka 
mata kepada para pembaca bahwa keamanan sangat lah penting dan harus diperhatikan di zaman modern dengan perkembangan teknologi yang semakin pesat saat ini.

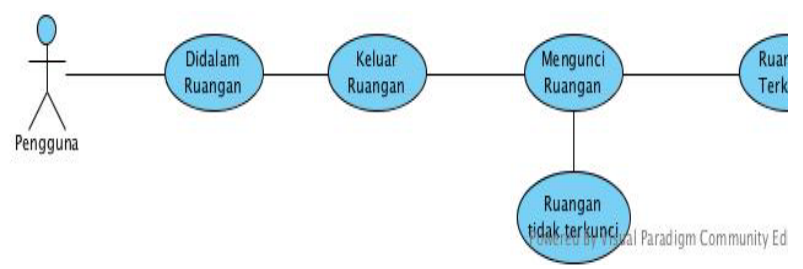

Gambar 1. Alur Keluar Ruangan

\subsection{Pemecahan Masalah}

Dari permasalahan yang telah dijabarkan diatas maka diperlukannya sebuah sistem yang mampu meningkatkan sistem keamanan yang ada sebelumnya. Jika pada sistem keamanan sebelumnya sudah ada kamera CCTV untuk mengawasi siapa saja yang masuk ruangan tersebut, namun belum bisa membatasi siapa saja yang dapat memasuki pintu ruangan tersebut. Maka sistem penguncian otomatis dinilai sangat cocok untuk meningkatkan sistem keamanan tersebut. Hal tersebut dilandasi dengan metode yang digunakan oleh sistem tersebut dengan menetapkan waktu kapan terbukanya atau terkuncinya ruangan tersebut menggunakan waktu yang telah ditetapkan. Maka jika seseorang keluar ruangan dan lupa menguncinya, ruangan tersebut akan terkunci dengan waktu yang telah ditetapkan. Hal ini masih belum efektif karena bisa saja oknum memasuki ruangan sesaat setelah pemilik ruangan meninggalkan ruangan tersebut. Karena hal tersebut penerapan fingerprint pada penguncian otomatis tersebut sangatlah diperlukan. Dengan adanya sistem pengamanan fingerprint dapat mengidentifikasi dan membatasi siapa saja yang memasuki ruangan tersebut. Selain itu dengan fingerprint pemilik ruangan dapat mengunci ruangan dengan sidik jari miliknya kapanpun diluar waktu yang telah ditetapkan. Hal ini membuat sistem keamanan menjadi lebih canggih dan modern karena sidik jari manusia tidak dapat dimanipulasi atau digandakan sehingga tingkat keamanan sebuah ruangan menjadi lebih baik. Pemilik ruangan menjadi tenang ketika meninggalkan ruangan tersebut.

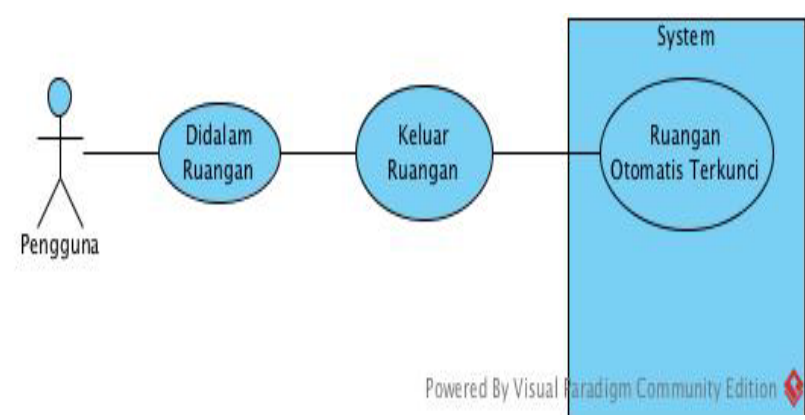

Gambar 2. Alur pemecah masalah

Tujuan dari dilakukannya penelitian ini adalah untuk meningkatkan sebuah ruangan yang saat ini sering disepelekan oleh kebanyakan orang serta menyadarkan bahwa keamanan sangatlah 
penting utnuk menjaga arsip atau dokumen penting bahkan rahasia pada sebuah lembaga pemerintahan, pendidikan atau perusahaan. Penelitian ini juga bertujuan untuk memberikan rasa aman kepada setiap instansi baik pemerintah, pendidikan serta perusahaan besar yang memiliki dokumen dan arsip penting yang harus dijaga, khususnya perusahaan besar dokumen penting tidak boleh jatuh ke tangan pesaing mereka demi kemakmuran dan kesejahteraan perusahaan tersebut.

\subsection{Analisa Sistem Prototype}

Pada penelitian yang dilakukan ini, peneliti menganalisa prototype yang digunakan terdiri dari hardware dan software. Hardware pada prototype ini diantaranya sebagai berikut :

1. Arduino Uno

2. FPM10A Fingerprint Reader Sensor

3. RTC DS 3231

4. Solenoid Lock

5. Buzzer 5 volt

6. Relay Module

Selain menggunakan hardware untuk membuat prototype ini, sarana pendukung sebagai software juga diperlukan untuk kelancaran pembuatan prototype ini. Software yang peneliti gunakan pada penelitian ini adalah Arduino IDE. Mengapa peneliti menggunakan software Arduino IDE dalam pembuatan Prototype ini? Karena setiap prototype yang menggunakan Arduino dalam pembuatannya, berarti otak dari prototype tersebut adalah Arduino. Untuk mengkonfigurasi arduino tersebut digunakanlah Arduino IDE.

Adapun susunan hardware pembuatan prototype ini dibuat dalam blok diagram yang menggambarkan alur dari prototype yang dibuat. Berikut merupakan contoh Blok Diagram prototype pengunci pintu otomatis :

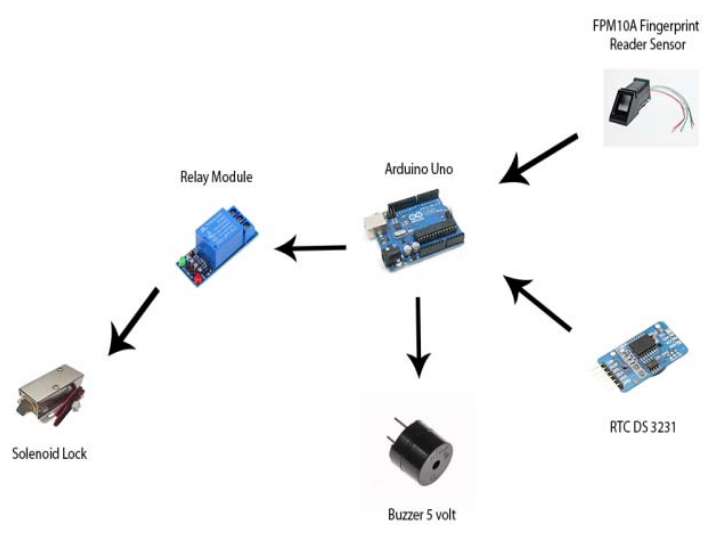

Gambar 3. Blok Diagram Prototype

Dengan adanya blok diagram diatas memudahkan pembaca untuk melihat alur prototype tersebut. Berikut penulis jelaskan alur dari prototype tersebut berdasarkan blok diagram diatas :

1. Fingerprint membaca sidik jari yang telah diinput 
2. Selanjutnya data Fingerprint mengirimkan data yang telah diinput menuju Arduino

3. Arduino lalu melakukan proses Autentikasi data sidik jari untuk mengaktifkan relay dan membuka Solenoid Lock

4. Kemudian, untuk RTC berfungsi untuk menyimpan waktu yang diinginkan untuk dapat mengunci dan membuka pintu secara otomatis.

Untuk lebih jelasnya dalam memahami prototype ini, peneliti menambahkan skema prototype ini dalam pada gambar di bawah ini :

そ

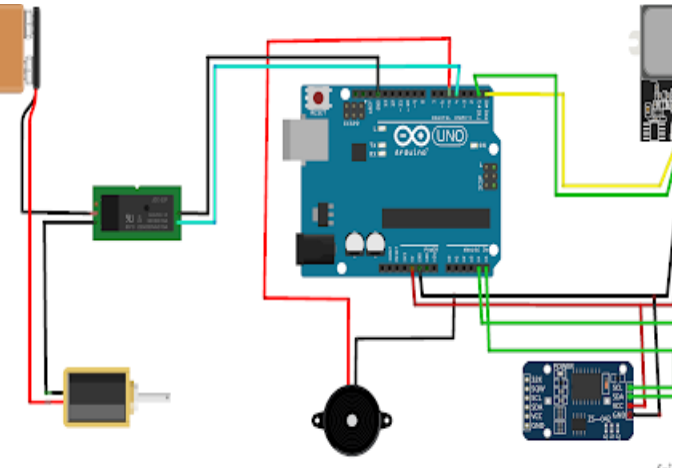

Gambar 4. Skematik Rangkaian

Penjelasan dari skema prototype diatas adalah sebagai berikut :

1. Kabel berwarna merah untuk mengkoneksikan sumberdaya power dari arduino ke seluruh rangkaian
2. Kabel kuning dan hijau pada fingerprint sensor untuk menghubungkan menuju pin RX dan TX pada arduino

3. Kabel coklat untuk menghubungkan hardware dengan ground

4. Kabel hijau pada untuk menghubungkan Timer dengan Arduino

5. Kabel biru untuk mengaktifkan solenoid

Diatas merupakan blok diagram dan skema yang akan diterapkan pada prototype pengunci pintu otomatis.

\section{SIMPULAN}

Peningkatan keamanan tidak boleh disepelekan pada era modern saat ini yang semakin pesat perkembangan teknologinya. Keamanan juga sangatlah penting untuk menjaga keaslian dokumen dan menjaga rahasia lembaga institutional. Penerapan prototype pengunci pintu otomatis dinilai mampu untuk meningkatkan keamanan demi menjaga dokumen dan arsip lembaga institutional. Penggunaan biometrik sidik jari pada prototype pengunci pintu otomatis sangat bagus untuk membatasi orang yang ingin memasuki ruangan. 


\section{DAFTAR PUSTAKA}

[1] Supriyono, H., Kurniawan, A., \& Rakhmadi, A. (2013). Perancangan

Dan Pembuatan Sistem Pintu Otomatis Menggunakan Barcode.

[2] Rurungan, J., Nugraha, D. W., \& Anshori, Y. (2014). Sistem Pengaman Pintu Otomatis Menggunakan Radio Frequency Identification (RFID) Tag Card Dan Personal Identification Number (PIN) Berbasis Mikrokontroler AVR Atmega 128. Mektrik, 1(1).

[3] Sofyan, A. A., Puspitorini, P., \& Baehaki, D. (2017). Sistem Keamanan Pengendali Pintu Otomatis Berbasis Radio Frequency Identification (RFID) Dengan Arduino Uno R3. Jurnal Sisfotek Global, 7(1).

[4] Budiarto, R. (2018). Kinerja Algoritma Pengenalan Wajah Untuk Sistem Penguncian Pintu Otomatis Menggunakan Raspberry - Pi. Khazanah Informatika: Jurnal Ilmu Komputer Dan Informatika, 3(2), 8087.

[5] Nur, M. (2016). Miniatur Pengaman Pintu Otomatis Berbasis Mikrokontroler (Doctoral Dissertation, Politeknik Negeri Padang).
[6] Apriadi, A., Nasution, S. M., \& Azmi, F. (2016). Perancangan Otentikasi Sidik Jari Pada Sistem Biometric Payment. Eproceedings Of Engineering, 3(1).

[7] Junaidi, J., Anugrah, L., \& Pancasakti, A. D. (2015). Model Aplikasi Monitoring Sistem Absensi Sidik Jari Sebagai Pendukung Keputusan Untuk Penilaian Kinerja Pegawai. Proceedings Konferensi Nasional Sistem Dan Informatika (KNS\&I).

[8] Wahyudi, R., Soesanto, O., \& Muliadi, M. (2016). Rancang Bangun Aplikasi Pengenalan Pola Sidik Jari. KlikKumpulan Jurnal Ilmu Komputer, 2(1), 74-83.

[9] Taufiq, Rohmat. 2013. Sistem Informasi Manajemen. Yogyakarta: Graha Ilmu.

[10] Simarmata, Janner. 2013. "Rekayasa Perangkat Lunak”. Yogyakarta: CV Andi Offset.

[11] Zahruddin, M., Handayani, I., \& Santika, N. (2018). Merancang Sistem Pengolahan Atk Berbasis Web Pada Pt. Arthaasia Finance. Ccit Journal, 11(2), 225-235. 